Dokuz Eylül Üniversitesi-Mühendislik Fakültesi

Fen ve Mühendislik Dergisi

Cilt 19, Sayı 57, Eylül 2017
Dokuz Eylul University-Faculty of Engineering Journal of Science and Engineering Volume 19, Issue 57, September 2017

DOI: $10.21205 /$ deufmd.2017195786

\title{
Isı Değiştiricili Hava Sızdırmalı Güneş Toplayıcılarının Teorik ve Deneysel İncelemesi Hacer AKHAN ${ }^{* 1}$, Doğan ERYENER ${ }^{1}$,
}

${ }^{1}$ Trakya Üniversitesi, Mühendislik Fakültesi, Makine Mühendisliği Bölümü, 22100, Edirne

(Alınış / Received: 29.03.2017, Kabul / Accepted: 07.06.2017, Online Yayınlanma / Published Online: 20.09.2017)

Anahtar Kelimeler Hava sızdirmalı güneş toplayıcısı, Kilcal borulu radyant Isitma sistemi, Güneş enerjisi ile hava isitma
Özet: Hava sızdırmalı güneş toplayıcıları, güneş enerjisini kullanarak, bina ısitma havalandırması ve kurutma uygulamalarında hava ısıtması yapan sistemlerdir. Hava sızdırmalı güneş toplayıcısının performansı önemli ölçüde güneş ışınım şiddetine bağlıdır. Bu çalışmada, bir tamamlayıcı ısıtma sistemi olarak, kılcal boru ısı değiştiricisi ile desteklenmiş hava sızdırmalı güneş toplayıcısının, güneş ışınımının olmadı̆̆ koșullardaki etkinliği belirlenmiștir. Kılcal borulu entegrasyonlu hava sızdırmalı güneş toplayıcısı teorik ve deneysel olarak incelenmiştir. Farklı su debisi, hava debisi ve sıcak su sıcaklıkları için, kılcal borular ile güneş toplayıcısı arasındaki ısı transferi etkinliği deneysel olarak incelenmiştir. Kılcal boru isı transferi etkinliğinin, farklı koşullar için 0.45 ile 0.77 arasında değiştiği belirlenmiş, güneşin yetersiz olduğu durumlar için kılcal boru sisteminin hava sızdırmalı toplayıcılar için uygun bir tamamlayıcı sistem olabileceği tespiti yapılmıştır.

\section{Theoretical and Experimental Investigation of Transpired Solar Air Collector Coupled to a Heat Exchanger}

\begin{abstract}
The transpired solar collector uses the solar energy to preheat ventilation air for buildings and agricultural applications. The thermal performance of transpired collector is depending on solar radiation significantly. In this study, the effectiveness of the transpired solar collector coupled to a capillary heat exchanger as a supplementary heating system has been determined for nonsolar conditions. A theoretical and experimental analysis were carried out regarding perforated solar air collector which is coupled to a capillary heating system. Heat transfer effectiveness between the capillary tubes and the solar collector is investigated experimentally for different conditions such as mass flow rates, inlet temperatures. It has been determined that capillary tube heat transfer efficiency varies between 0,45 and 0,77 for different conditions, and the capillary tube system can be suitable supplementary system for transpired solar collector when the solar radiation is insufficient.
\end{abstract}




\section{Giris}

Günümüzde fosil yakıtların bina ısıtmasında kullanılmasıyla ortaya çıkan çevresel sorunları azaltabilmek ve önleyebilmek için güneş enerjisiyle ısıtma teknolojileri etkin bir yöntem olarak yaygınlaşmaktadır. Ayrıca, gün geçtikçe artan enerji maliyetlerinin azaltılması için güneş enerjisi sistemleri ön plana çıkmaktadır. Güneș enerjisinden faydalanmanın en etkili yöntemlerinden birisi, ısıl güneș enerjisi uygulamalarıdır. Isıl güneş uygulamalarında yaygın olarak sıcak su üretimi ön plana çıkmakla birlikte, özellikle son on yllda gerek dünyada gerekse Türkiye'de güneșle hava isitma sistemleri uygulamalarının hızla yaygınlaştı̆̆ gözlemlenmektedir. Güneşle hava ısıtma sistemlerinin hızlı yaygınlaşmasının temelinde yatan nedenlerden birisi, güneș duvarı olarak cephe kaplaması şeklinde uygulaması yapılan, yüksek verimli hava sızdırmalı güneş toplayıcılarının geliştirilmiş olmasıdır [1, 2]. Hava sızdırmalı güneș toplayıcıları, daha yüksek verimli olması, cephe kaplama şeklinde uygulanabilmesi, yapısının basit olması, uzun malzeme ömrü ve düşük geri ödeme süreleri nedenleriyle, konvansiyonel olarak kabul edilebilecek diğer güneşle hava isıtma sistemlerine göre uygulamada önemli bir üstünlük sağlamıștır ve dünya çapında ön plana çıkmıştır.

Hava sızdırmalı güneș toplayıcılarının en önemli özelliklerinden birisi, güneşle ısıtma işleminin taze hava kullanılarak gerçekleştirilmesidir, böylece isıtma ve havalandırma işlemleri bir arada yapılmaktadır. Illk olarak John Hollick [3] tarafından seksenli yıllarda geliştirilmiş olan hava sızdırmalı güneș toplayıcılarının temel ısı transferi teorisi, Kutscher ve Christensen tarafindan tanımlanmıştır [4]. Kutscher, hava sızdırmalı toplayıcılar için Isı transferi denklemleri geliştirmiştir [5]. Van Decker üç boyutlu akış için ısı transfer etkinliğini araştırmıştır [6]. Van Decker ve Hollands, rüzgarsız koşullarda, kare veya üçgen dizilimli dairesel delikler için etkinlik denklemini geliştirmiştir [7, 8]. Gunnewiek ve arkadaşları, rüzgarın toplayıcıya olan etkisini incelemiştir [9]. Leon ve Kumar güneș enerjisi ile kurutma için hava sızdıralı güneş toplayıcılarının analizini yapmıștır [10]. Motahar ve Alemrajabi, hava sızdırmalı güneş toplayıcılarının ekserji analizini incelemiştir [11]. Li ve arkadaşları, hava sızdırmalı güneş toplayıcısına entegre edilmiş fotovoltaik sistemin performans analizini ve enerji modellemesini yapmıșlardır [12, 13]. Vasan, rüzgarın hava sızdırmalı güneş toplayıcısı üzerindeki etkisini incelemiştir [14].

Özellikle son on yılda yapılan çalışmalar ile hava sızdırmalı güneș toplayıcılarının çalışma prensipleri ve önemi daha iyi anlaşılmıştır. Bu noktada, pek çok araştırmacı, hava sızdırmalı güneş toplayıcılarının geliştirilmesi ve performans artışının sağlanması için yeni yöntemler önermişlerdir. Nowzari ve arkadaşları, kısmi sızdırmalı havalı güneş toplayıcısı prototip çalışması yapmıştır [15]. Shen ve arkadaşları, dahili kanatçıklı kompakt güneş enerjili cephe sistemi tasarlamıştır [16]. Badache ve arkadaşları, şeffaf hava sızdırmalı güneş toplayıcısı prototipi geliştirmiştir [17]. Janusevicius ve arkadaşları, entegre hava sızdırmalı toplayıcı-1sı pompası çalışması yapmışlardır [18]. Shams ve arkadaşları, performans artışı için yoğunlaștırılmıș hava sızdırmalı toplayıcı prototipi geliştirmişlerdir [19]. Razak ve arkadaşları, havalı güneş toplayıcıları için matrix yapıda absorber panel tasarlamıştır [20]. Zomorodian ve Zamania, gözenekli yapıdaki absorber üzerinden kademeli cam kullanımı ile hava sızdırma performansını arttıran bir yöntem önermiştir [21]. Vaziri, Ilkan ve Egelioğlu, hava sızdırmalı güneş toplayıcılarının farklı iç yüzey 
renklerinde sağladığı performansı deneysel olarak incelemiştir [22]. Zheng ve arkadaşları, soğuk iklim koşullarında hava sızdırmalı toplayıcı performansını arttırmak için yeni bir tasarım yapmışlardır [23]. Hall, hava sızdırmalı toplayıcılar için seçici yüzeyli absorber önermiş ve performans incelemesi yapmıştır [24]. Croitoru ve arkadaşları, hava sızdırmalı absorber panelin için yeni bir delik sistemi tasarlamıştır [25]. Güneşin yetersiz olduğu durumlar için hava sızdırmalı toplayıcıların sürekliliğini sağlamak amacıyla Eryener, ısı değiştiricili toplayıcı önerilmiştir [26]. Eryener ve Akhan [27], Eryener [26] tarafından önerilen sistemin ön incelemesini ve kullanılabilirliğini, laboratuvar test ünitesi ve hesaplamalı akışkanlar dinamiği ile yapmışlardır. Akhan [28], Eryener ve Akhan [27] tarafından ön incelemesi yapılmış sistemin endüstriyel kullanılabilirliğini doktora tezi kapsamında yapmış olduğu deneysel fabrika hacim isitması uygulaması ile belirlemiştir. Bu çalışma, söz konusu doktora çalışması kapsamında, Eryener ve Akhan [27] tarafından ön incelenmesi yapılmış ısı değiştiricili güneş toplayıcısı çalışmasının devamı niteliğinde olup, toplayıcıda kullanılan ısı değiştiricisinin, su debisi, su sicaklığı ve giriş-çıkış sıcaklıklarına bağlı olarak değișen farklı ısıtma kapasiteleri için toplayıcı performansının değişimi, farklı toplayıcı işletme koşulları için parametrik olarak incelenmiş ve laboratuvarda elde edilmiş test sonuçları ile karşılaştırılarak, sistemin genel esasları ve çalıșma prensipleri ortaya konmuştur.

\section{Sistem Tanımı}

2.1.Hava sızdırmalı güneş toplayıcıları Hava sızdırmalı güneș toplayıcıları, metal malzemeden üretilmiş binaların güney, güney-doğu, güney-batı dış cephelerine monte edilen, havalandırma ve güneşle hava isitma sistemleridir. Sistemin en önemli elemanı güneş enerjisini absorbe eden hava sızdırmalı absorber paneldir. Absorber panelin yapısal özelliği, düşük emisivite değerine ve yüksek absorbsiyon özelliğine sahip olmasıdır. Hava sızdırmalı güneş toplayıcıları, absorber panel birim alanındaki çok sayıda özel tasarımlı milimetrik delikleri sayesinde, dış havayı güneş enerjisi ile ısıtarak iç ortama göndermektedir. Havalandırma kanalına yerleștirilen fan çalıştırıldığında, duvar ile absorber yüzey arasındaki hacimde (toplayıcı iç hacminde) vakum oluşmaktadır. Oluşan vakum etkisi ile dış ortam havası deliklerden toplayıcı iç ortamına emilmektedir. $\quad 0.8 \quad \mathrm{~mm}$ çapındaki deliklerin içinden hava, sınır tabaka akışı ile geçmektedir. $\mathrm{Bu}$ hava hareketi esnasında absorber panelin ısısı, havaya transfer edilmektedir. Isınan hava, toplayıcı iç hacminin üst bölgesine doğru hareket etmekte ve sonra da fan aracılı̆̆ ile bina iç ortamına gönderilmektedir.

\subsection{Kılcal boru sistemleri}

Kılcal borulu isı değiștiricisi, ısıtmasoğutma, jeotermal ve endüstri uygulamaları için özel tasarlanmış, iç çapları 0,76 ile 3,5 $\mathrm{mm}$ arasında değişen çok sayıda borunun bir araya getirmesiyle oluşturulmuş isl değiştiricisidir. İç çapı çok küçük olduğu için kılcal boru adı verilmektedir. Kılcal borulu sistemler, bina içi ısıtma-soğutma uygulamalarında kullanılmaktadır.

Deney tesisatındaki kılcal borular ve sisteme ait bütün parçalar fusiolen polipropilen (R-80) malzemesinden üretilmiștir. Deney tesisatında kullanılan kılcal borular için Almanya'da faaliyet gösteren Beka und Klima Heizung GMBH firmasının ürünü olan P.VG10 kodlu model seçilmiştir. Fusiolen polipropilen (R-80) malzemeden üretilmiş kllcal boruların başlıca özellikleri fiziksel dayanıklılık, kimyasal nötrlük, güvenilir olması, ısı transfer yüzeyinin fazla olması, düşük maliyet, düşük sürtünme faktörüdür. 
Kılcal boruları tanımlayan ilk çalışmalar 1940’lı yıllarda yayınlanmıștır. Bu zaman dilimi içerisinde yayınlanan iki önemli makale R. H. Swart ve L. A. Staebler tarafından yazılmıştır [29, 30]. Swart, ilk olarak kılcal borular içerisindeki soğutucu akışkanların termodinamik özelliklerini tanımlamıștır. Steabler, farklı kılcal boru uzunlukları ve çaplarının soğutucu akışına etkisini araștırmış ve farklı çalıșma koşulları için kılcal boru geometrileri seçiminde kullanılan bir tablo oluşturmuştur. Hopkins, optimum kılcal boru boyutlarını belirlemek için kullanılan iki model tanımlamıştır [31]. Whitesel, adyabatik akış varsayımı ile bir model geliştirmiştir [32]. Cooper, iki fazlı akışı tanımlamıştır [33]. Mikol, akış alanındaki işi ve sürtünme faktörü hesaplamalarını belirlemiştir [34]. Erth, kılcal boru boyutlandırması için iki bilgisayar kodu oluşturmuştur [35]. Goldstein, adyabatik ve adyabatik olmayan prosesler için bir model geliştirmiştir [36]. Sweedyk, kılcal borular içindeki duvar pürüzlülüğündeki değişkenliği göstermek için profilometre ölçümlerini kullanmıştır [37]. Pate, Goldstein'in yaptığına benzer bir model sunmuştur [38].

\subsection{Isı değiştiricili hava sızdırmalı güneş toplayıcısı}

Isı değiştiricili hava sızdırmalı güneş toplayıcısı, ilk olarak Eryener tarafından önerilmiş bir sistemdir [26]. Amaç, güneş ışınımının olmadığı veya yetersiz olduğu durumlarda, tamamlayıcl bir sistem olarak toplayıcı içerisinde isıtma yapmasıdır. Sistem, güneşin ışınım şiddetinin az olduğu kış aylarında bile önemli oranda ısıtma maliyeti azalması ve enerji kazancı sağlamaktadır.

$\mathrm{Bu}$ çalışmada, ısı değiştiricisi olarak ağırlıklı olarak ışınım ile ısı transferi sağladığı için kılcal borulu ısı değiştiricisi kullanılmıştır. Şekil 1'de laboratuvar koşullarında kurulumu yapılan kılcal borulu hava sızdırmalı toplayıcının içyapısı görülmektedir. Isı değiştiricili hava sızdırmalı güneş toplayıcısı; kılcal borulu ısı değiştiricisi, delikli absorber panel ve arka plakadan oluşmaktadır. Toplayıcı iç hacminde, arka plakaya monte edilen kılcal borulu ısı değiştiricisi yer almaktadır. Isıtma sistemlerinde kılcal borular içerisinden sıcak su akışı olmaktadır. Sıcak su akışı ile toplayıcı iç ortamına isı transferi yapılmaktadır. Kılcal borulu ısı değiştiricisi etkisiyle, mahal iç ortamı ile mahal diş ortamı (toplayıcı iç ortamı) arasındaki sıcaklık farkı daha fazla küçülmektedir. Ayrıca duvardan olan ısı kayıpları toplayıcı iç ortam havasina transfer edilmektedir. Böylece mahal iç ortamından olan isı kayıplarının azalması ve duvardan kaybolan ısının geri kazanımı gerçekleştirilmektedir. Güneş enerjisinin olmadığ zamanlarda da sistem, enerji tasarrufu yapmaya devam etmektedir. Kılcal borulu ısı değiștiricisi etkisiyle, güneş ışınım şiddetinin düşük olduğu mevsim koşullarında bile toplayıcı daha yüksek verim ile çalışmaktadır. Böylece kılcal borulu hava sızdırmalı günes toplayıcıları sistemlerinin genel olarak düşük olan geri ödeme süresi daha da kısalmaktadır. Bu, kılcal borulu hava sızdırmalı güneş toplayıcılarının en önemli avantajıdır. 
H. Akhan, D. Eryener / Isı Değiştiricili Hava Sızdırmalı Güneş Toplayıcılarının Teorik ve Deneysel İncelemesi

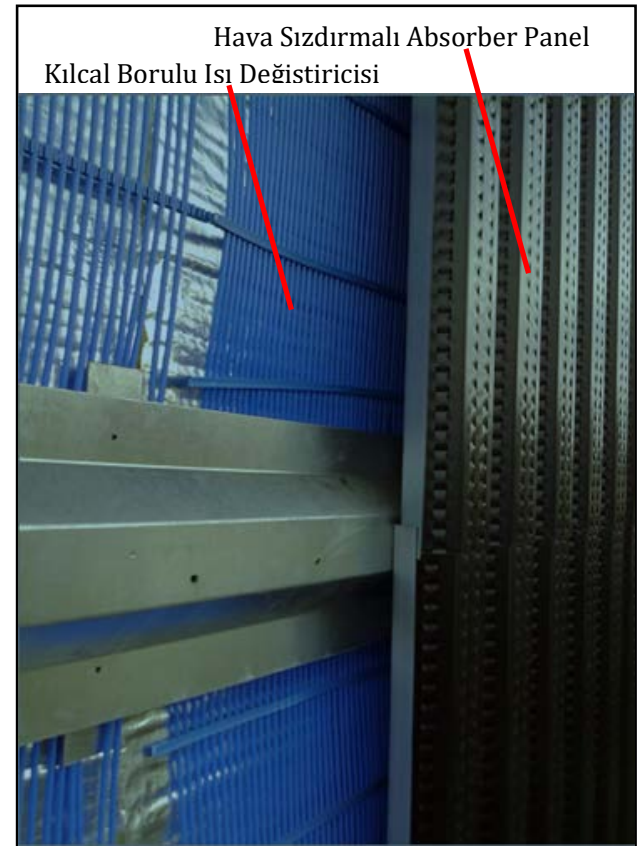

Şekil 1. Laboratuvarda kurulumu yapılan kılcal borulu hava sızdırmalı güneş toplayıcısının içyapısı

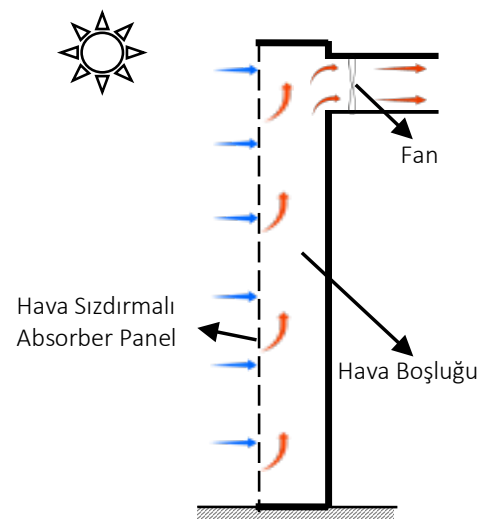

(a)

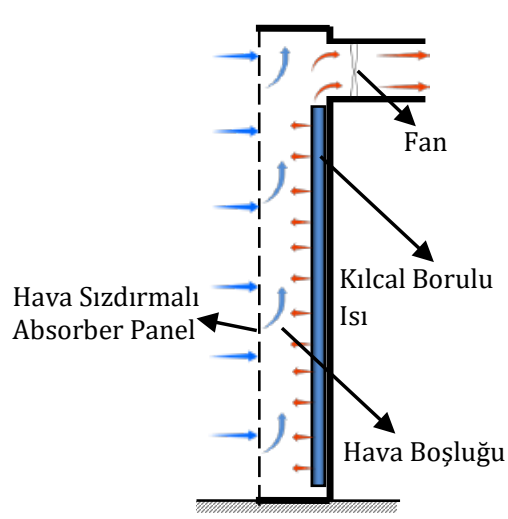

(b)

Şekil 2. (a)Standart hava sızdırmalı toplayıcı ve (b) ısı değiștiricili toplayıcı șematik resmi

\subsection{Kılcal borulu toplayıcının enerji denge denklemleri}

Kılcal borulu toplayıcı için enerji denge denklemi dört ana bileşenden (absorber panel, kılcal borulu ısı değiștiricisi, hava ve arka plaka) oluşmaktadır. Şekil 3'te ısı transfer mekanizması şematik olarak gösterilmiştir. Sisteme enerji girişi, güneș ışınımı ve kılcal borulu ısı değiștiricisi ile gerçekleşen isı transferi ile olmaktadır. Sistemdeki net kayıplar, arka plakadan ve absorber panelden ışınım ve taşınım ile isı transferi sebebiyle gerçekleşmektedir.

\section{Absorber panel}


H. Akhan, D. Eryener / Isı Değiştiricili Hava Sızdırmalı Güneş Toplayıcılarının Teorik ve Deneysel İncelemesi

$$
\begin{aligned}
& \mathrm{m}_{\mathrm{abp}} \times \mathrm{c}_{\mathrm{p}, \mathrm{abp}} \times\left(\mathrm{dT}_{\mathrm{abp}} / \mathrm{dt}\right)=\left(\alpha_{\mathrm{abp}} \times\right.
\end{aligned}
$$

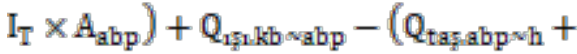

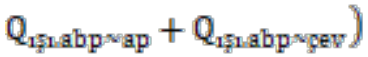

$Q_{\text {tagaabp } / h}$ terimi, absorber panelden havaya (absorber ön yüzeyinden, delik ve arka plakadan toplayıcı iç ortam havasına yapılan ısı transferini içeren) ISı

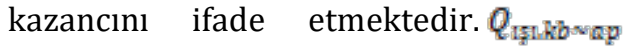
kılcal borular ile arka plaka arasındaki ışınım ile gerçekleşen Isı transferidir. $Q_{1 p_{1 p \text { abp }} \text { ap }}$ absorber panelden arka plakaya olan ışınım ile ısı transferini ifade etmektedir. $Q_{1 \text { pr.abpwçev, }}$ absorber yüzeyden çevreye olan ışınım ile ısı kaybıdır. $\mathrm{m}_{\mathrm{abp}}$ absorber panelin kütlesi, $\mathrm{c}_{\mathrm{p}, \mathrm{abp}}$ absorber panelin özgül ısınma 1sısl, $\mathrm{T}_{\mathrm{abp}}$ absorber panel sıcaklığıdır.

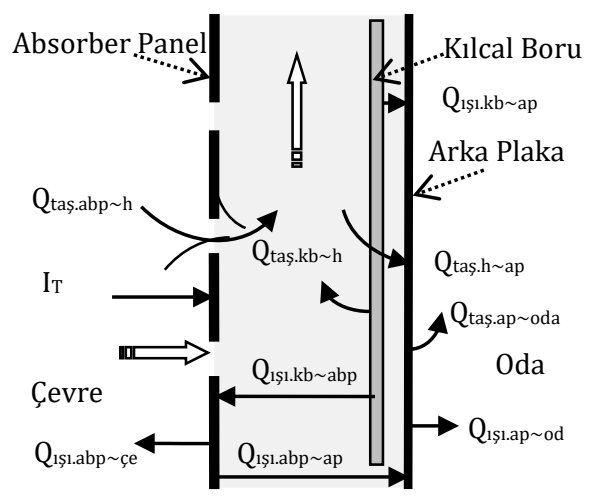

Şekil 3. Kılcal borulu hava sızdırmalı güneş toplayıcısındaki isı transferi mekanizması [28]

\section{Toplayıcı iç ortam havası}

$$
\begin{aligned}
& \left(\mathrm{m}_{\mathrm{h}} \times \mathrm{dt}\right) \times \mathrm{c}_{\mathrm{ph}} \times\left(\mathrm{dT}_{\mathrm{h}} / \mathrm{dt}\right)=
\end{aligned}
$$

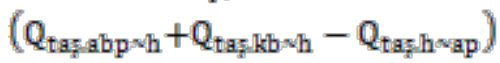

Denklem 2'deki $\quad Q_{\text {tag } k b \text { wh }}$ kılcal borulardan toplayıcı iç hacim havasına taşınım ile yapılan ısı transferini ifade etmektedir. $Q_{\text {tag } h \text { wap }}$, toplayılcı içindeki hava akımı ile arka plaka arasındaki ısı transferi ifadesidir. $\mathrm{m}_{\mathrm{h}}$ toplayıcı iç ortam havasının debisi, $\mathrm{c}_{\mathrm{p} . \mathrm{h}}$ havanın özgül ısınma ısısı, $\mathrm{T}_{\mathrm{h}}$ toplayıcı iç ortam havası sıcaklığıdır.

\section{Kılcal Boru Sistemi}

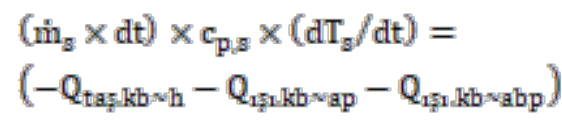

(3)

Denklem 3'teki Q $Q_{\text {tagkbwh }}$ toplayıcı içindeki hava akımı ile kılcal boru arasındaki taşınım ile isı transferi, $Q_{\text {เq̣ikb wap, }}$ arka panel ile kllcal boru arasındaki ışınım ile ısı transferi,

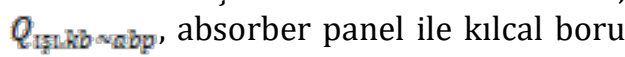
arasındaki ışınım ile gerçekleşen ısı transferi ifadeleridir. $\mathrm{m}_{\mathrm{s}}$ kılcal boru su debisi, $c_{p . s}$ suyun özgül ısınma isısı, $T_{s}$ kılcal boru suyunun sıcaklı̆ı̆ıdır.

\section{Arka Plaka}

$$
\begin{aligned}
& \mathrm{m}_{\mathrm{ap}} \times \mathrm{c}_{\mathrm{p}, \mathrm{ap}} \times\left(\mathrm{dT}_{\mathrm{ap}} / \mathrm{dt}\right)=\left(\mathrm{Q}_{\mathrm{ta} g \mathrm{~h} / \mathrm{ap}}+\right.
\end{aligned}
$$

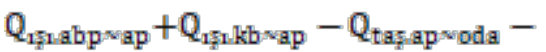

$$
\begin{aligned}
& Q_{\text {17̣ıap voda }} \text { ) }
\end{aligned}
$$

$\mathrm{Q}_{\text {tagsap voda, }}$ arka plakadan mahal iç ortamına taşınım ile gerçekleşen ısı transferini ifade etmektedir. $Q_{1 p_{1} \text { เap voda }}$ arka plakadan mahal iç ortamına ışınım ile transfer edilen Isıdır. $m_{a p}$ arka plakanın kütlesi, $c_{\text {p.ap }}$ arka plakanın özgül ısınma isısı, $T_{\text {ap }}$ arka plaka sıcaklı̆̆ıdır.

\section{Kılcal Boru Isı Transfer Denklemleri}

Sistemdeki ısı değiştiricisi, dairesel geometrili kllcal boru demetlerinden oluşmaktadır. Su, kılcal boruların içinden 
geçmekte, farklı sıcaklığa sahip olan hava ise boru demetinin dışından, borulara ters akım oluşturarak akmaktadır. Bu şekilde, isının sıcak olan sudan havaya aktarılması, bir başka deyişle havanın isitılması (veya suyun soğuması) sağlanmaktadır. Şekil 4'te, dikey konumlu kılcal borular ile toplayıcı iç ortam havası arasındaki ters akıș șeması yer almaktadır.

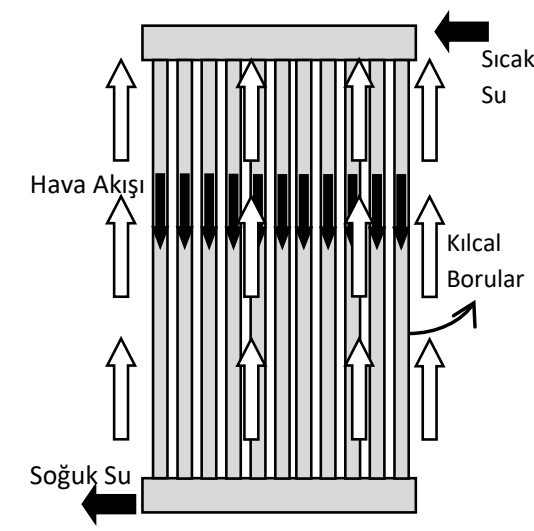

Şekil 4. Kılcal borular ile toplayıcı iç ortam havası arasındaki ters akış şeması [28]

Kılcal boru 1Sı değiştiricisini oluşturan borular, düzgün tek sıralı diziliștedir. Kilcal borular ile hava arasında zorlanmış taşınım ile ısı transferi gerçekleşmektedir. Kılcal boruların çevresindeki taşınım katsayısı, yaklaşık olarak, tek bir boru çevresindeki akıma ait taşınım katsayısına eşittir.

Kılcal borulu ısı değiştiricisi dış akışı incelenirken, bir boru demeti için ortalama taşınım katsayısına ait bağıntıların kullanımında gerekli olan Reynolds sayısı $R e_{\mathbb{D}}$, akışkan hızının maksimum olduğu değere göre tanımlanmaktadır.

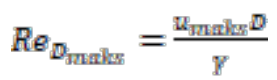

$u_{\text {maks }}$ maksimum hızl, D kilcal boru çapını, $y$ kinematik viskoziteyi ifade etmektedir. Düzgün sıralı kılcal boru demeti için maksimum hız, kılcal borular arasındaki kesitte oluşmaktadır. Şekil 5 'te dairesel kesitli kılcal boru sistemi kesit görünümü yer almaktadır. Sıkıștırılamaz akıșkanlar için süreklilik gereği kütle korunumundan faydalanarak 6 nolu bağıntı elde edilmektedir.

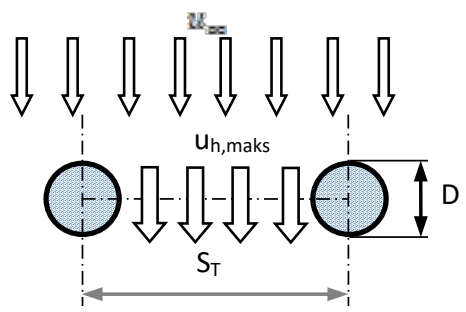

Şekil 5. Dairesel kesitli kılcal boru sistemi kesit görünümü [39]

$u_{\mathrm{sc}} S_{T}=u_{\text {maks }}\left(S_{T}-D\right)$

$S_{T}$ iki kılcal borunun merkez çizgisi arasındaki mesafe, $u_{m}$ hava hızı olarak tanımlanmaktadır. Denklem 6'dan faydalanarak maksimum hız, denklem 7 ile ifade edilmektedir.

$u_{m a k s}=u_{s a c} \frac{s_{T}}{S_{T}-D}$

Kılcal borulardaki ortalama taşınım ile ısı transferi katsayısının belirlenmesi, toplam ısı transfer katsayısını bulmak için yeterli değildir. Çünkü kılcal boru yüzey sıcaklığı ve hava sıcaklığı arasındaki sıcaklık farkı, kılcal boru boyunca değişmektedir. $\Delta T$ sabit değildir. Newton'nun soğuma yasasında logaritmik ortalama sicaklık farkı kullanılmaktadır. Logaritmik ortalama sıcaklı farkı $\Delta T_{\text {lm }}$, denklem 8 kullanılarak hesaplanmaktadır.

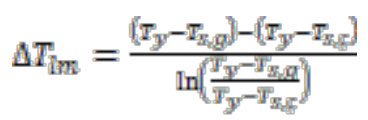

$\mathrm{T}_{\mathrm{s}, \mathrm{g}} \quad \mathrm{su}$ giriş sıcaklığgl, $\mathrm{T}_{\mathrm{s}, \mathrm{c}}$ kılcal boru sisteminden suyun çıkış sıcaklığl, $\mathrm{T}_{\mathrm{y}}$ kılcal boru yüzey sıcaklığı ve $\mathrm{N}$ kılcal 
boru sayısıdır. Kılcal boru uzunluğu başına toplam isı transferi $Q$, denklem 9 ile hesaplanmaktadır.

$Q=N \bar{h} \pi D \Delta T_{\mathbb{l n}}$

$\mathrm{N}$ kılcal boru sayısı, $\bar{h}$ ortalama taşınım ile ısı transferi ısı taşınım katsayısıdır. Kılcal borulardan toplayıcı iç ortam havasına gerçekleşen ısı transferi, toplayıcı iç ortam havasına verilen enerjiye eşit olacaktır. $\mathrm{Bu}$ nedenle isı transferi denklem 10 ile ifade edilebilmektedir.

$Q=m_{g} c_{p}\left(T_{\text {gg }}-T_{\text {gig }}\right)$

Kılcal boruların içinden akan suyun kütlesel debisi $\dot{m}$, denklem 11 ile hesaplanmaktadır.

$\dot{m}=\rho u_{s a} N_{T} S_{T}$

$\mathrm{N}_{\mathrm{T}}$, hava akışı yönüne paralel olan kılcal boru satırlarının sayısı, $\rho$ yoğunluktur. Kılcal borulardan toplayıcı iç ortam havasına yapılan isı transferi, denklem 12 ile hesaplanmaktadır.

$Q=\rho u_{\mathrm{so}} N_{T} S_{T} c_{p}\left(T_{\text {sg }}-T_{\text {gg }}\right)$

Denklem 9 ve 12 kendi aralarında birbirine eşitlenirse, 13 nolu denklem elde edilmektedir.

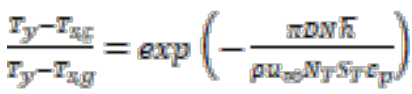

Denklem 13, kılcal boru sistemindeki su çıkış sıcaklığını bulmak için kullanılmaktadır.

Kılcal borulu hava sızdırmalı güneş toplayıcısının ısı değiştirme etkinliği $\varepsilon_{H X}$, denklem 14 ile hesaplanmaktadır.

$\varepsilon_{H X}=\frac{T_{h y}-T_{h g}}{T_{r, g}-T_{h g}}$
$\mathrm{Bu}$ çalışmada, ısı değiştirme etkinliği hesaplanırken absorber panel sıcaklığı hesaba katılmamaktadır. Çünkü bu çalışma güneş ışınım şiddetinin olmadığg koşullar için ısı değiştirme etkinliğini vurgulamaktadır. Bu nedenle, absorber panel üzerinde güneş enerjisi ısıtma etkisinin olmadığ varsayılmaktadır.

\section{Deney tesisatı}

Kılcal borulu hava sızdırmalı güneş toplayıcısındaki ısı transferini ve sistem parametrelerinin etkinlik üzerine etkisini incelemek amaciyla laboratuvar koşullarında kontrollü deneylerin yapılabileceği bir model kurulmuştur. $\mathrm{Bu}$ modelde hava debisi, dış hava sıcaklığı, su debisi, kılcal boru su giriş sıcaklığ farklı değerlerde alınarak, kılcal borulu radyant ısıtma sistemi ile toplayıcı ic ortam havası arasındaki ısı transferi karakteristiği belirlenmiştir. Laboratuvar çalışmalarında güneş ışınımı simüle edilmemiș, sadece kılcal borulu radyant ısı değiştiricisi çalıștırılarak kılcal boruların ısıtma etkisi ele alınmıştır.

Laboratuvar koşullarında kurulumu yapılan sistemin eni $2 \mathrm{~m}$, boyu $2,5 \mathrm{~m}$ ve derinliği 0,1 m'dir. Sistemde $5 \mathrm{~m}^{2}$ delikli absorber panel kullanılmıştır. Hava sizdirmalı absorber paneller, oluklu geometridedir. Absorber panel üzerinde metrekarede ortalama 2500 tane $0,8 \mathrm{~mm}$ çapında delik yer almaktadır. Absorber panel ile arka plaka arasındaki mesafe 10 cm'dir. Arka plakaya $3 \mathrm{~cm}$ mesafe ile kılcal borular monte edilmiştir. Sistemde

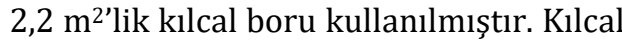
borular, $3 \mathrm{~mm}$ çapındadır ve polipropilen malzemeden üretilmiştir. Şebekeden gelen soğuk su, eğitim amaçlı kullanılan minyatür bir kazanda isitılarak, bir sirkülasyon pompası aracılığı ile kılcal borulara gönderilmektedir. Sicak su kılcal borulardan geçerken ısısını taşınım ile havaya, ışınım ile toplayıcı iç yüzeylerine transfer etmektedir. Sıcaklığg 
H. Akhan, D. Eryener / Isı Değiştiricili Hava Sızdırmalı Güneş Toplayıcılarının

Teorik ve Deneysel İncelemesi

azalan su atı su kanalına tahliye edilmektedir. Kılcal boru çıkış hattında kullanılan küresel vana kısılarak, borulardaki suyun basınçlandırılması sağlanmıştır.

Sistemin tüm dıș yüzeyleri yalıtılmıştır. Delikli absorber yüzeyinin önünde $0,3 \mathrm{~m}$ derinliğinde hava boşluğu oluşturacak şekilde, yalıtım malzemesi ile kapalı bir

iklimlendirme deney tesisatı ile ayarlanabilen değerlerdeki düşük sıcaklıklarda hava gönderilmiștir. $\mathrm{Bu}$ sayede delikli absorber panelin diș yüzeyinde kış mevsimi soğuk hava koşulları sağlanmıștır. Şekil 6'da laboratuvar koşullarında kurulumu yapılan kılcal borulu ısı değiştiricili toplayıcının şematik resmi ve ölçüm noktaları şematik resmi görülmektedir.

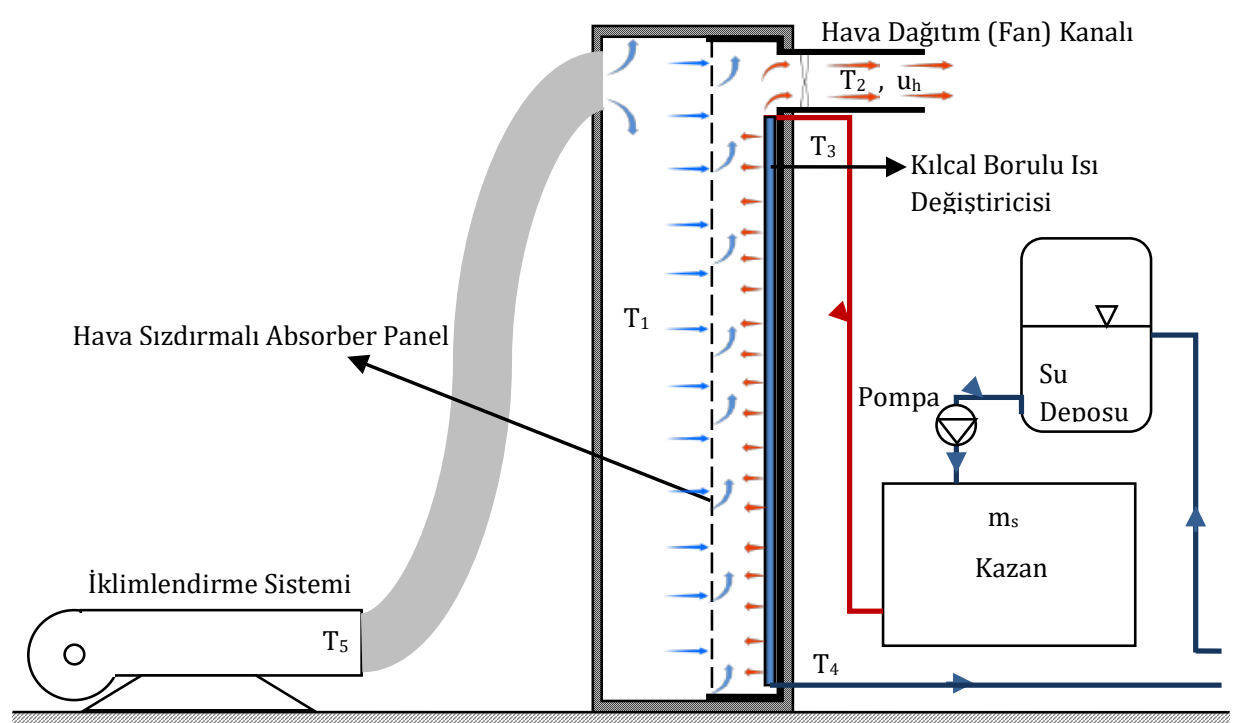

Şekil 6. Deney tesisatının ve ölçüm noktalarının şematik resmi

Tablo 1. Deney tesisatı ölçüm yerleri ve elemanları

\begin{tabular}{ll}
\hline Ölçme Elemanı & Ölçüm Yeri \\
Sıcaklık sensörü-PT100 & T1-Yalıtımlı soğuk hava kanalı \\
Sıcaklık sensörü-PT100 & T2-Fan kanalı hava çıkışı \\
Sıcaklık sensörü-PT100 & T3-Kılcal boru girişi \\
Sıcaklık sensörü-PT100 & T4-Kılcal boru çıkışı \\
Sıcaklık sensörü-PT100 & T5-İklimlendirme sistemi çıkışı \\
Rotametre & ms-Kazanda kılcal boru su debisi ölçümü ve ayarı \\
Anemometre & uh- Fan kanalı hava çıkışı \\
Klape & İklimlendirme sistemi çıkışı \\
Veri Kaydedici Cihaz & Her bir ölçüm noktası \\
\hline
\end{tabular}

Arka plakanın üst orta bölgesinde bir üzerindeki deliklerden toplayıcı iç tane fan kullanılmıștır. Fan ortamına emilmektedir. Bu çalıșmanın çalıştırıldığında toplayıcı iç ortamında amacı, kılcal borulu ısı değiștiricisinin vakum oluşmaktadır. Oluşan vakumun toplayıcı performansındaki etkisini etkisiyle soğuk hava, absorber panel incelemektir. Bu nedenle güneş ışınımı 
etkisi sistemde simüle edilmemiştir. Güneş ışınımı ısıtma etkisi olmadığı için absorber panel sıcaklığı, soğuk hava sıcaklığına çok yakın bir değerdedir. Diğer bir ifadeyle absorber panelin toplayıcı iç ortamına emilen havanın sıcaklığını arttırma etkisi yoktur. Havanın sıcaklığındaki artış, kılcal borulu radyant isı değiștiricisi ile sağlanmaktadır. Isınan hava fan aracılığı ile laboratuvar iç ortamına gönderilmektedir.

Sisteminin kritik noktalarında sıcaklık, hava hızı ve su debisi ölçümleri yapılmıştır. Kılcal boru giriş ve çıkış bölgelerinde, dıș hava koşullarının simüle edildiği soğuk hacimde, toplayıcı iç ortamında, sıcak hava dağıtım kanalı çıkışında sıcaklık ölçümü yapılmıştır. Bu bölgelerde sıcaklık ölçümü için PT100 tipi sıcaklık sensörleri kullanılmıştır. Yapılan ölçümler dijital göstergeli datalogger cihazı ile kaydedilmiştir. Su debisini ölçmek ve ayarlamak için rotametre kullanılmıştır. Rotametre, kazan çıkıșına monte edilmiș ve buradan su debisi ayarı da yapılmıştır. Hava debisini belirlemek için de fan kanalındaki hava akış hızı ölçülmüştür. Kanalın kesit alanı bilinmektedir. Alan ile hızın çarpımından hava hacimsel debisi hesaplanmaktadır.

\section{Sonuçlar ve Tartışma (Bulgular)}

Yapılan deneysel çalışmalarda, ölçülen değerlerden faydalanılarak kılcal boruların isıtma kapasitesi, etkinlik ve kılcal borular ile toplayıcı iç ortam havası arasındaki ısı taşınım katsayısı değerleri hesaplanmıștır. Grafik 1, 2, 3 ve 4 laboratuvar çalışmaları deneysel veriler, grafik 5, 6 ve 7 teorik analiz sonuçları kullanılarak elde edilmiştir.

Grafik 1'de, dıș ortam sıcaklığ $\mathrm{T}_{\mathrm{dıs}}=12^{\circ} \mathrm{C}$ ve su debisi $m_{s}=16,5 \mathrm{~kg} / \mathrm{h} / \mathrm{m}^{2}$ de farklı kılcal boru giriş suyu sıcaklıkları için hava çıkış sıcaklığının hava debisine göre değişimi görülmektedir. Sabit kılcal boru giriş suyu sıcaklığı için, hava debisi arttıkça, hava çıkış sıcaklığı azalmakta, dolayısıyla da etkinlik azalmaktadır. Hava debisinin sabit değerlerinde kılcal boru giriș suyu sıcaklığı arttıkça hava çıkış sıcaklığı artmakta ve bu nedenle de etkinlik değeri yükselmektedir.

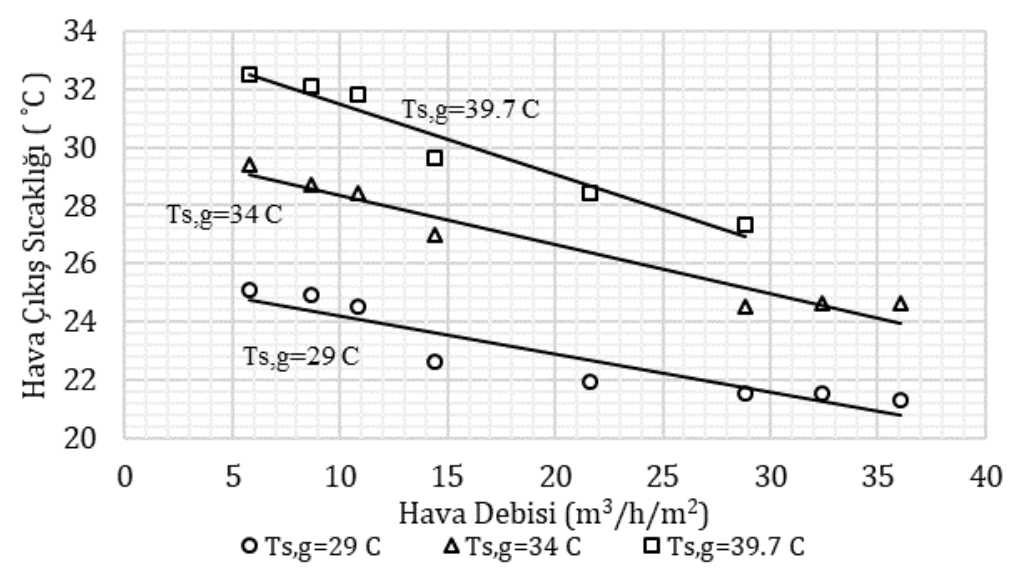

Grafik 1. $\mathrm{T}_{\mathrm{d} \iota s}=12{ }^{\circ} \mathrm{C}$ ve $\mathrm{m}_{\mathrm{s}}=16,5 \mathrm{~kg} / \mathrm{h} / \mathrm{m}^{2}$ de farklı kılcal boru giriş suyu sıcaklıkları için hava çıkış sıcaklığının hava debisine göre değișimi

Grafik 2'de, dış ortam sıcaklığı $\mathrm{T}_{\text {dıs }}=12{ }^{\circ} \mathrm{C} \quad$ suyu sıcaklıklarında etkinliğin hava ve $16,5 \mathrm{~kg} / \mathrm{h} / \mathrm{m}^{2}$ kılcal boru su akışı debisine göre değişimi yer almaktadır. kütlesel debisi için, farklı kılcal boru giriş Hava debisi arttıkça etkinlik 
azalmaktadır. Sabit hava debisi için kılcal boru giriş suyu sıcaklığı arttıkça etkinlik artmaktadır. Yüksek giriş suyu sıcaklığında ve düşük hava debisinde, en yüksek etkinlik değeri elde edilmektedir.

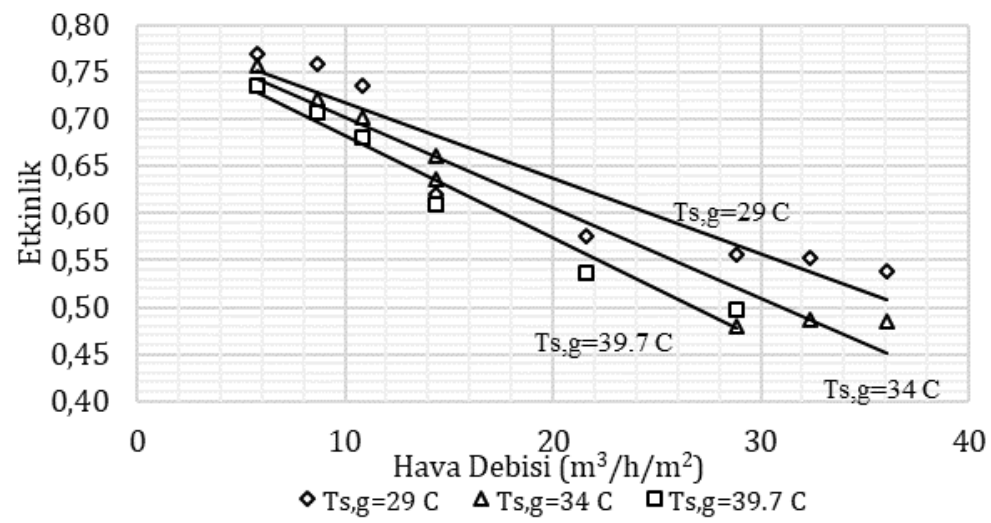

Grafik 2. $\mathrm{T}_{\mathrm{d} ı s ̧}=12{ }^{\circ} \mathrm{C}$ ve $\mathrm{m}_{\mathrm{s}}=16,5 \mathrm{~kg} / \mathrm{h} / \mathrm{m}^{2}$ 'de farklı kılcal boru giriș suyu sıcaklıkları için etkinliğin hava debisine göre değișimi

Grafik 3'te $\mathrm{T}_{\mathrm{dıs}}=12{ }^{\circ} \mathrm{C}$ ve kılcal boru giriş suyu sıcaklığı $\mathrm{T}_{\mathrm{s}, \mathrm{g}}=29.1^{\circ} \mathrm{C}^{\prime}$ de farklı kılcal boru su debisi değerleri için etkinliğin hava debisine göre değişimi görülmektedir. Su debisinin sabit değeri için, hava debisi arttıkça hava çıkış sıcaklığı azalacağından dolayı etkinlik azalmaktadır. Hava debisinin sabit değeri için, kılcal boru su debisi arttıkça, kılcal boruların ısıtma kapasitesi ve hava çıkıs sıcaklığı yükselmekte, dolayısıyla etkinlik artmaktadır. En yüksek etkinlik değeri hava debisinin düşük, su debisinin yüksek olduğu değerlerde elde edilmektedir.

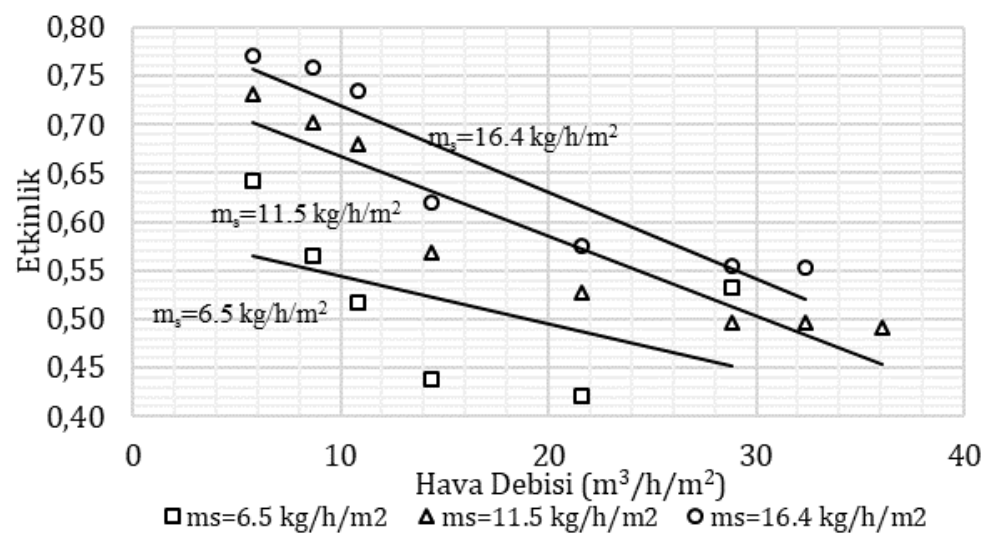

Grafik 3. $\mathrm{T}_{\mathrm{d} \iota s ̧}=12{ }^{\circ} \mathrm{C}$ ve $\mathrm{T}_{\mathrm{s}, \mathrm{g}}=29.1^{\circ} \mathrm{C}$ 'de farklı kılcal boru su debisi değerleri için etkinliğin hava debisine göre değișimi

Grafik 4'te, hava debisi $\mathrm{m}_{\mathrm{h}}=20 \mathrm{~m}^{3} / \mathrm{h} / \mathrm{m}^{2}$, kılcal boru su debisi $\mathrm{m}_{\mathrm{s}}=11,45 \mathrm{~kg} / \mathrm{h} / \mathrm{m}^{2}$, hava giriş sicaklığl $\mathrm{T}_{\mathrm{h}, \mathrm{g}}=\mathrm{T}_{\mathrm{d} \iota s}=10^{\circ} \mathrm{C}$ değerleri için kılcal borular ile toplayıcı iç ortam havası arasındaki ısı transfer katsayısının hava sıcaklık artışı ile değişimi yer almaktadır. Yapılan deneylerde kılcal boru giriş suyu 
Sicaklığ $\mathrm{T}_{\mathrm{s}, \mathrm{g}}=28,30,32,34,36,38,40^{\circ} \mathrm{C}$ değerlerindedir. Grafikten görüldüğü gibi hava sızdırmalı güneş toplayıcılarındaki isı transfer katsayısı, toplayıcı giriş ve çıkış havası arasındaki sıcaklık farkı arttıkça artmaktadır.

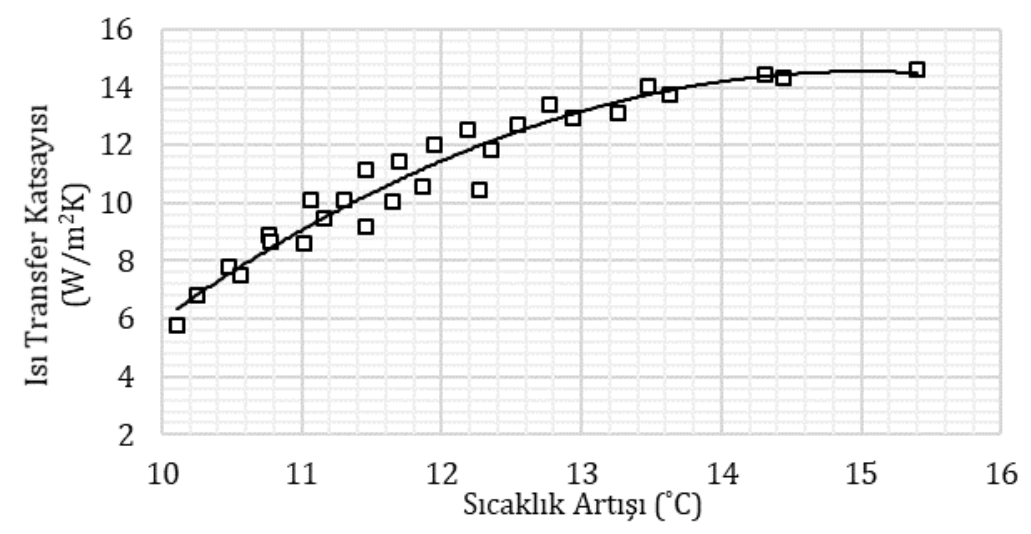

Grafik 4. Kılcal borular ile toplayııı iç ortam havası arasındaki ısı transfer katsayısının hava sıcaklık artışı ile değişimi

Denklem 1-14 aralığında verilen denklemler kullanılarak kılcal boru sistemi ile hava sızdırmalı toplayıcı arasındaki ISı transferi ve etkinliğin değişimi farklı işletme parametreleri için grafik 5-7'de verilmiştir.

Grafik 5'te kılcal boru ile toplayıcı havası arasındaki ısı transferi katsayısının, farklı hava debileri ve sıcaklık artışları için değişimi verilmiştir. Teorik ısı transferi değerlerinin, deneysel olarak belirlenmiş Isı transfer katsayılarının benzer bir eğilim çizgisine sahip olduğu grafik 4 ve 5 'ten görülmektedir. Toplayıcıda belirli bir sıcaklık artışı için, ısı transferinin hava debisi ile orantılı olarak arttırdığı görülmektedir. Kılcal boru-toplayıcı havası arasındaki sıcaklık farkının etkisi, ISı transferi üzerindeki daha önemli rol oynamaktadır. Bununla birlikte absorber yüzeyden sızdırılan hava miktarının performansta belirli bir etkisi vardır.

Grafik 6'da farklı kılcal boru isitma kapasiteleri için, hava debisinin sıcaklık artışına olan etkisi verilmektedir. Hava debisi artışının sıcaklık artışına etkisi çok büyük değildir. Bununla birlikte belirli bir hava debisi için, kılcal boru isı kapasitesinin sıcaklık artışına etkisi daha önemli olmaktadır ki deneysel elde edilmiş sonuçlara benzer bir davranış önceki bölümlerde grafik 3'te de görülmektedir 


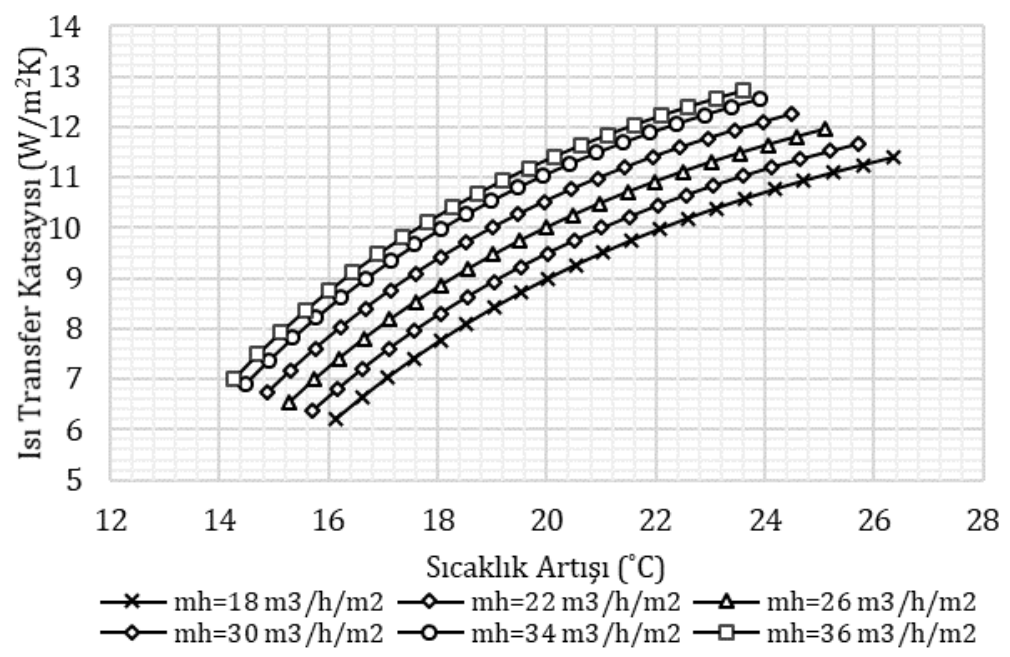

Grafik 5. Farklı hava debileri için hava sıcaklık artışının ısı transfer katsayısı ile değişimi

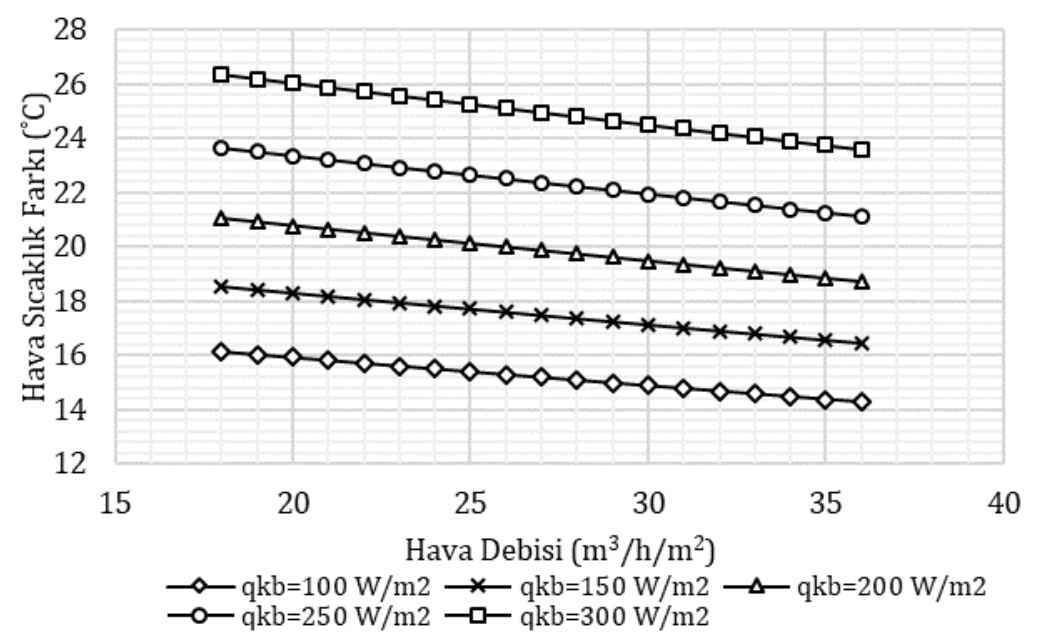

Grafik 6. Farklı kılcal boru ısıtma kapasiteleri için hava sıcaklık farkının hava debisi ile değişimi

Tüm ısı değiştiricisi sistemlerinde olduğu gibi, isı transferi etkinliği, sistem performansı belirleyen bir unsurdur. Grafik 7'de kılcal boru-hava sızdırmalı toplayıcl uygulamasının isl transferi etkinliği verilmektedir. Genel olarak, endüstride kullanılan sıcak su- hava isı değiştiricilerinde etkinlik değerleri, 0.250.4 aralığında, oldukça çok düşük değerlere sahiptir. Bu durum kompakt yapıdaki ısı değiştiricisinin yüzey alanının, uygulamada yeterince yayılamamasından kaynaklanmaktadır. Bununla birlikte, kilcal boru uygulamalarında, ısı transfer yüzeyi büyük alanlara yayılmaktadır. Bu durum, hava sizdırmalı toplayıcı uygulaması içinde geçerlidir ki bu aynı zamanda daha 
düşük sıcaklıkta su sevki imkanının sağlamaktadır. Dolayısıyla, kılcal boru hava sızdırmalı toplayıcı etkinliğinin, klasik uygulamalara göre yüksek olması beklenen bir sonuçtur. Grafik 7'de görüldüğü üzere, etkinliğin teorik olarak 0.75'e kadar çıktığı görülmektedir. Benzer sonuçlar, deneysel çalışmalar ile de belirlenmiștir. Hava debisi etkinlik üzerinde önemli olmakla birlikte, tıpkı önceki grafikte açıklandı̆̆ı üzere, ıSı kapasitesi daha büyük rol oynamaktadır.

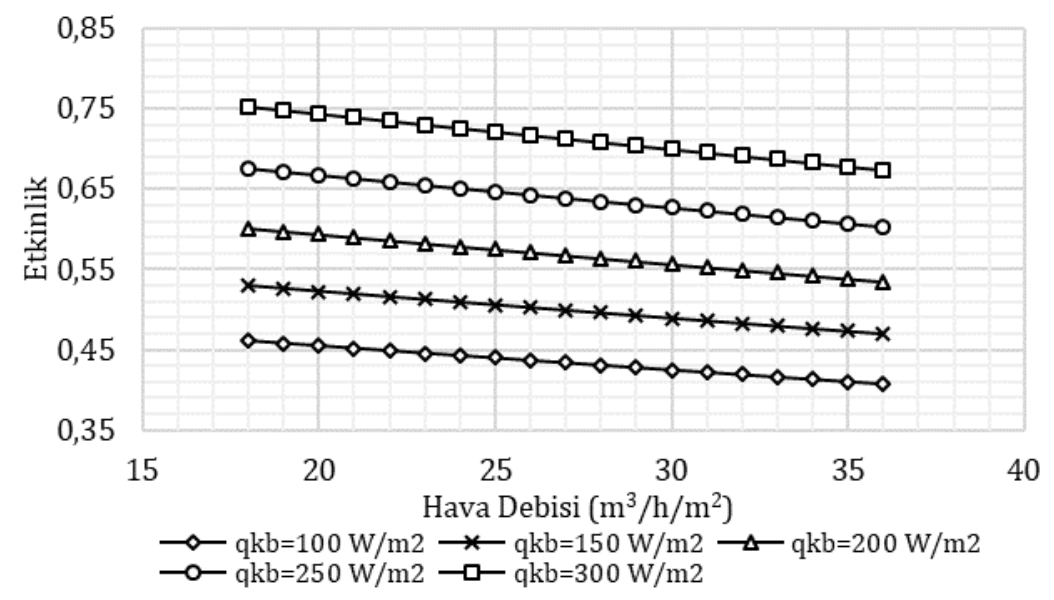

Grafik 7. Kılcal boru ısıtma kapasitesinin farklı değerleri için etkinliğin hava debisi ile değişimi

\section{Sonuçlar}

Bu çalışmada, ısı değiştiricisi olarak bina ısıtmasinda uygulamalarında yaygin şekilde kullanılan kılcal boru sistemleri, hava sızdırmalı toplayıcıya entegre edilmiştir. Farklı işletme parametreleri için ISı değiştiricisinin performansı belirlenmiștir. Güneșin yetersiz olduğu durumlarda, toplayıcı içine entegre edilmiş ısı değiştiricisine sıcak su sevki yapılarak, hava ısıtma işleminin belirli bir seviyede sürekliliğin sağlanabileceği görülmüștür. Bu ișlem yapılırken, 0.45 ile 0.77 arasında değişen isı transferi etkinlikleri elde edilmiștir, dolayısıyla dahili ısı değiştiricisi uygulaması, iyi bir tamamlayıcı sistem potansiyeline sahiptir. Dahili Isı değiştiricisi uygulaması, hava sızdırmalı toplayıcılar için genel bir performans artışı sağlamaktadır ve fonksiyonel çalışmasının, güneşin olmadığı zaman dilimine yaymaktadır. Öte yandan, genel uygulaması kışın hacim ısıtması amaçlı olan ve büyük duvarlar üzerine kurulan klasik hava sızdırmalı toplayıcıları, dahili ısı değiştiricisi uygulaması sayesinde, atıl olarak bulundukları yaz mevsiminde, sıcak su üretme potansiyeline sahip olacaktır. $\mathrm{Bu}$ durum, çok büyük bir yüzeyden tüm bir yıl boyunca efektif olarak faydalanma imkanını sağlayacaktır.

Farklı kılcal boru isıtma kapasiteleri, su ve hava debileri için, kılcal borulu hava sızdırmalı güneş toplayıcısının sağladığı sıcaklık artışının ortalama $27^{\circ} \mathrm{C}$ ile $15^{\circ} \mathrm{C}$ arasında değiştiği belirlenmiş, güneşin yetersiz olduğu durumlar için kılcal boru sisteminin hava sızdirmalı toplayıcilar için uygun bir tamamlayıcı sistem olabileceği tespiti yapılmıștır.

\section{Kaynakça}

[1] NREL Bulletin - Solar Buildings Transpired Sola Collectors Ventilating Preheating DOE/GO102001-1288, Haziran 2006 
[2] Shuklaa, A., Nkwetta, D. N., Choa, Y.J., Stevensona, V., P., Jones, P., 2012. A state of art review on the performance of transpired solar collector, Renewable and Sustainable Energy Reviews, Cilt. 16, s. 3975-3985

[3] Hollick J.C. 2003. Unglazed Solar Wall Air Heaters, Conserval EngineeringInc., 200 Wildcat Rd. Downsview, Ontario M3J 2N5, Canada,

[4] Kutscher, C.F.,Christensen, C., Barker, G. 1993. Unglazed transpired solar collectors: heat loss theory. ASME Journal of Solar Engineering, Cilt. 115, s. $182-188$

[5] Kutscher, C. F. 1993. An Investigation of Heat Transfer for Air Flow Through Low Porosity Perforated Plates, University of Colorado, Boulder, 289 sayfa

[6] Van Decker, G.W.E.,Hollands, K.G.T., Brunger, A.P. 1996. Heat Exchange effectiveness of unglazed transpired-plate solar collector in 3D flow. In: Goietzburger, A., Luther, J. (Eds.), Proceedings of EuroSun 96, Freiburg, Germany. DGSSonnenenergie Verlags $\mathrm{GmbH}$, Munchen, Almanya, s. 130-846

[7] Van Decker, G.W.E.,Hollands, K.G.T. 1999. An empirical heat transfer equation for the transpired solar collectors, including no-wind conditions. In: Proceedings of the ISES 99 Solar World Congress, Australia

[8] Van Decker, G.W.E., Hollands, K.G.T., Brunger, A.P. 2001. Heat Exchange relations for unglazed transpired solar collectors with circular holes on a square or triangular pitch. Solar Energy, Cilt. 71, s. 33-45

[9] Gunnewiek, L.H. Brundrett, E., Gunnewiek, L.H. 1996. Flow distribution in unglazed transpired plate solar air heaters of large area, Solar Energy, Cilt. 57, s. 227
[10] Leon, M., Kumar, A., S., Leon, M. Augustus. 2007. Mathematical modeling and thermal performance analysis of unglazed transpired solar collectors, Solar Energy, Cilt. 81, s. 62-75

[11] Motahar S, Alemrajabi AA. 2010. An analysis of unglazed transpired solar collectors based on exergetic performance criteria, International Journal of Thermodynamics. Cilt. 13, s. $153-60$

[12] Li , S., Karava , P. 2014. Energy modeling of photovoltaic thermal systems with corrugated unglazed transpired solar collectors - Part 2:Performance analysis, Solar Energy, Cilt. 102, s. 297-307

[13] Li , S., Karava , P., Currie, S., Lin , W. E., Savory, E. 2014. Energy modeling of photovoltaic thermal systems with corrugated unglazed transpired solar collectors - Part 1: Model development and validation, Solar Energy, Cilt. 102, s. 282-296

[14] Vasan, N. 2014. Theodore Stathopoulos, Experimental study of wind effects on unglazed transpired collectors, Solar Energy, Cilt. 101, s. 138-149

[15] Nowzari, R., Aldabbagh, L.B.Y., Egelioglu, F. 2014. Single and double pass solar air heaters with partially perforated cover and packed mesh, Energy, Cilt. 73, s. 694-702

[16] Shen, J., Zhang, X., Yang, T., Tang, L., Cheshmehzangi, A., Wu, Y., Huang, G., Zhong, D., Xu, P., Liu, S. 2016. Characteristic study of a novel compact Solar Thermal Facade (STF) with internally extruded pinfin flow channel for building integration, Applied Energy, Cilt. 168, s. 48-64

[17] Badache, M., Hallé, S., Rousse, D. R., Quesada, G., Dutil, Y., An experimental investigation of a twodimensional prototype of a transparent transpired collector, 
H. Akhan, D. Eryener / Isı Değiştiricili Hava Sızdırmalı Güneş Toplayıcılarının

Teorik ve Deneysel İncelemesi

Energy and Buildings 68 (2014) 232-241

[18] Janusevicius, K., Streckiene, G., Bielskus, J., Martinaitis, V., Validation of unglazed transpired solar collector assisted air source heat pump simulation model, Energy Procedia 95 ( 2016 ) 167 174

[19] Shams, S.M.N., Mc Keever, M., Mc Cormack, S., Norton, B. Design and experiment of a new solar air heating collector, Energy 100 (2016) 374-383

[20] Razak, A.A., Majid, Z.A.A., Azmi, W.H., Ruslan, M.H., Choobchiane , Sh. Najafi, G., Sopian, K. 2016. Review on matrix thermal absorber designs for solar air collector, Renewable and Sustainable Energy Reviews, Cilt. 64, s. 682-693

[21] Zomorodian, A., Zamanian M. 2012. Designing and Evaluating an Innovative Solar Air Collector with Transpired Absorber and Cover, Renewable Energy, Cilt. 2012, ID 282538

[22] Vaziri, R., Ilkan, M., Egelioglu, F. 2015. Experimental performance of perforated glazed solar air heaters and unglazed transpired solar air heater, Solar Energy, Cilt. 119, s. 251-260

[23] Zheng, W., Li, B., Zhang, H., You, S., Li, Y., Ye, T. 2016. Thermal characteristics of a glazed transpired solar collector with perforating corrugated plate in cold regions, Energy, Cilt. 109, s. 781-790

[24] Hall, R., Blower, J. 2016. Lowemissivity transpired solar collectors, Energy Procedia, Cilt. 91, s. $56-63$

[25] Croitoru, C. V., Nastase, I., Bode, F. I., Meslem, A. 2016. Thermodynamic investigation on an innovative unglazed transpired solar collector, Solar Energy, Cilt. 131, s. 21-29
[26] Eryener D. 2009. Metal Cladding System with a Heat Exchanger System , Türk Patent Enstitüsü

[27] Eryener D. and Akhan H., 2012. Theoretical And Experimental Investigation Of Perforated Solar Air Collector Coupled To A Capillary Radiant Heatıng System, 9th International Conference on Heat Transfer Fluid Mechanics and Thermodynamics, 16-18 July 2012, Malta

[28] Akhan H., 2015. Kılcal Borulu Hava Sızdırmalı Güneş Toplayıcılarının Teorik Ve Deneysel İncelenmesi, (Doktora Tezi), Trakya Universitesi FBE Makina Muhendisligi Anabilim Dali (Tez Yöneticisi : Yrd. Doç. Dr. Doğan ERYENER).

[29] Swart, R. H. 1946. Capillary Tube Heat Exchangers, Refrigerating Engineering, Cilt. (Eylül), s. 221-224, 248-249

[30] Staebler, L. A. 1948. Theory and Use of a Capillary Tube for Liquid Refrigerant Control, Refrigerating Engineering, Cilt. (Ocak), s. 55-59

[31] Hopkins, N. E, 1950. Rating the Restrictor Tube: Method of Determining Flow Capacities For Freon-12 and Freon-22, Journal of the ASRE - Refrigerating Engineering, Cilt. (Kasım), s. 10871094

[32] Whitesel, H. A. 1957. CapillaryTwoPhase Flow, Part II, Refrigerating Engineering, s. 35-40

[33] Cooper, L., C. K. Chu, and W.R. Brishken, 1957, Simple Selection Method for Capillaries Derived from Physical Flow Conditions, Refrigerating Engineering, s.37-41

[34] Mikol, E. P. 1963. Adiabatic Single and Two-Phase Flow in Small Bore Tubes, ASHRAE Journal, Cilt. (Kasım), s. 75-86

[35] Erth, R. A. 1970. Two-Phase Flow in Refrigeration Capillary Tubes: Analysis and Predition, Doktora Tezi, Purdue Üniversitesi 
H. Akhan, D. Eryener / Isı Değiştiricili Hava Sızdırmalı Güneş Toplayıcılarının Teorik ve Deneysel İncelemesi

[36] Goldstein, S. D., P.E. 1981. A Computer Simulation Method For Describing Two Phase Flashing Flow in Small Diameter Tubes," ASHRAE Transactions, s. 51-60

[37] Sweedyk, J. M. 1981. CapillaryTubes - Their Standardization and Use," ASHRAE Transactions, s. 1069 1076

[38] Pate, M. B. 1982. A Theoretical and Experimental Analysis of Capillary Tube Suction Line Heat Exchangers," Doktora Tezi, Purdue Üniversitesi

[39] Glück, $\quad$ B., 1990. Waermevebertragung, Berlin 